\title{
"Why do we Need to Measure Trace Elements in Steel?"
}

\author{
J.J. Dufrane
}

Q-C/R\&D Division Manager, Fabrique de Fer de Charleroi, Belgium

\begin{abstract}
With the increase in performance requested by users in the last twenty years, steel makers have had to improve their melting operations dramatically. Numerous chemical elements are now controlled or eliminated at levels of $50 \mathrm{ppm}$ and below.Sinces it is difficult to give a rating to the importance of these elements, this paper lists a series of them alphabetically, and comments on them, non-exhaustively.

Control of these substances has led to improvements in :

- Mechanical characteristics at room and elevated temperatures, as well as creep resistance.

- Toughness and fracture mechanics at low temperature.

- Practical weldability

- Hot and cold formability

- Corrosion resistance in numerous media.
\end{abstract}

\section{Aluminium}

This element is extensively used for steel deoxidation. In order to improve the toughness behaviour at low temperatures $\left(-40{ }^{\circ} \mathrm{C} ;-60^{\circ} \mathrm{C}\right)$ of offshore structural steels, developments have been made with controlled Titanium additions forming nitrides or oxydes inclusions. For adequate distribution of these inclusions, $\mathrm{Al}$ must be controlled to levels below $50 \mathrm{pnm}$.

Another example is the particular case of cold rolled thin sheets of stainless steels. The presence of slivers and inclusion alignments on the surface of the finished products can be avoided by limiting the presence of aluminates.

\section{Arsenic}

This trace element is often associated with $\mathrm{Sn}$ and $\mathrm{Pb}$. See under the heading $\mathrm{Pb}$ the formulae in which $\mathrm{As}$ is involved.

Ferrous scrap melting and iron ores containing Arsenic are the sources of pollution.

\section{Bismuth}

Similar to Arsenic.

\section{Boron}

Limited additions $-\mathbf{5 - 2 0} \mathbf{~ p p m}$ - of this element are very effective. But excessively high levels $(30 \mathrm{pp}-50 \mathrm{ppm}$ ) can generate a reverse effect. (liquation phenomena during welding of stainless steel) Close control of the content in the liquid steel is needed.

Two major applications of Boron additions are :

+ Quenched and tempered steels with yield and tensile strengths in the range of $800-1500 \mathrm{~N} / \mathrm{mm} 2$

for abrasion resistance, earth moving equipment and cranes, bridges, penstocks.

+ Improvement of the hot deformation characteristics of stainless steels. 


\section{Calcium}

Inclusion shape control is used in steel in order to improve properties through the thickness and Hydrogen Induced Cracking resistance.

This is generally achieved by Calcium injection in the ladle of liquid steel. As a result, inclusions of the oxy-sulfide type containing $\mathrm{Ca}$ are observed in the final product.

Close control of the ratios between $\mathrm{Ca}, \mathrm{S}, \mathrm{O}$ at levels below $20 \mathrm{ppm}$ is needed.

Calcium treatment is also extensively used in order to improve the castability of liquid steel through the nozzles of the continuous casting machine.

\section{Carbon}

In order to achieve extra deep-drawing quality (EDDQ) for car bodies and beverage-can fabrication, ultra-low Carbon steels are needed.

Carbon content (as well as nitrogen content) needs to be lowered to levels of 10 to $15 \mathrm{pmm}$ and fixed by Titanium additions in order to achieve an interstitial free (IF) steel.

Another example of the need to lower the Carbon content of the steel is encountered in the case of soft magnetic NO electrical sheets.

In this case, in order to prevent magnetic ageing and core losses, interstitial and inclusion forming elements must be reduced according to a formula of the type :

$$
\mathrm{C}+\mathrm{N}+\mathrm{S} \leq \mathbf{5 0} \mathbf{p p m}
$$

associated with a very low Oxygen content.

\section{Hydrogen}

The drop in solubility of dissolved Hydrogen in ferritic steels causes flaking defects in heavy sections.

Precise determination of Hydrogen in the range : $1-5 \mathrm{ppm}$ is needed in order to monitor vacuum degassing treatments in the melting shop, possible rehydrogenation during casting and further soaking treatments and conversion sequence.

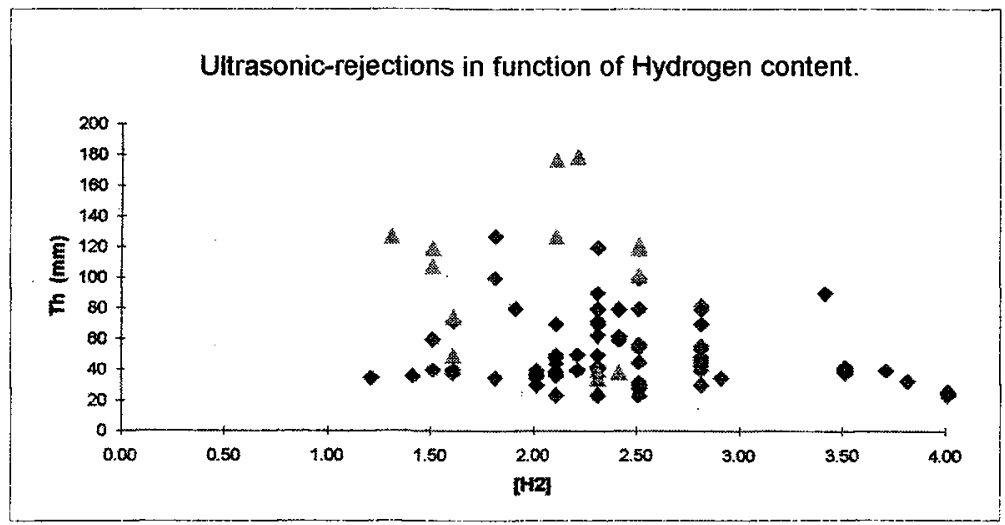

\section{Lead}

Although this element has very limited solubility in steel, its presence at levels of a few ppm has a negative influence on the hot workability of steel.

This is particularly true in the case of stainless steels as evidenced by the formula and the figures below. 


$$
\mathrm{Pb}_{\mathrm{eq}}=\mathrm{Pb}+2 \mathrm{Bi}+0.5 \mathrm{Te}+0.03 \times \mathrm{Sb}+0.02 \times \mathrm{Sn}+0.01 \times \mathrm{As}
$$

In practice, $\mathrm{Pb}$ content below $\mathbf{5} \mathrm{ppm}$ are aimed for and have to be controlled.

Forgeability curves according to L.F. Ljungström
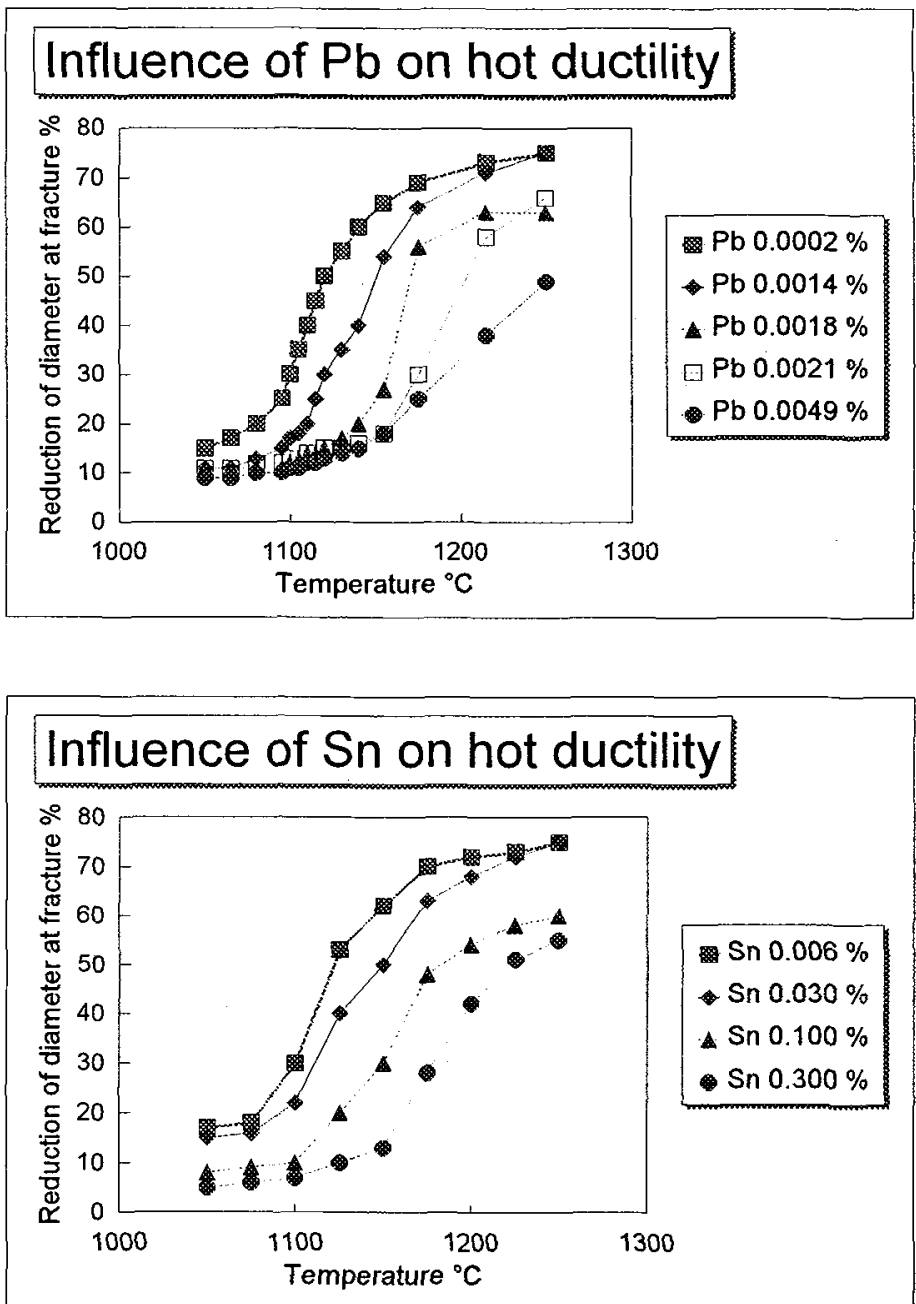


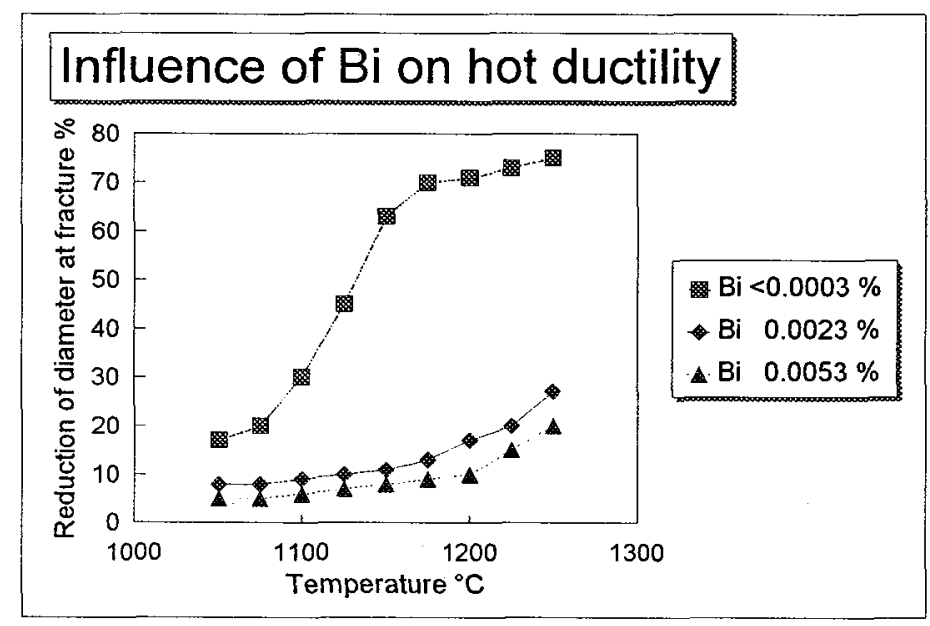

\section{Nitrogen}

See carbon for its interstitial influence in the case of thin sheets.

Additionally, in the case of thick section steels to be welded into heavy structures, in which stresses and strains can be very high (equal or superior to the yield strength of the material), strain ageing effects lowering the impact toughness at low temperature $\left(-40^{\circ} \mathrm{C}\right)$ of the welded joints can occur due to the presence of interstitial free Nitrogen.

In order to prevent this very serious problem, which threatens the integrity of the structure, Nitrogen contents are reduced to values below $\mathbf{5 0} \mathbf{~ p p m}$ and free Nitrogen is fixed with Aluminium or Titanium.

\section{OFFSHORE STRUCTURAL STEEL PLATE - $60 \mathrm{~mm}$}

ISO-V Transverse Transition Curve

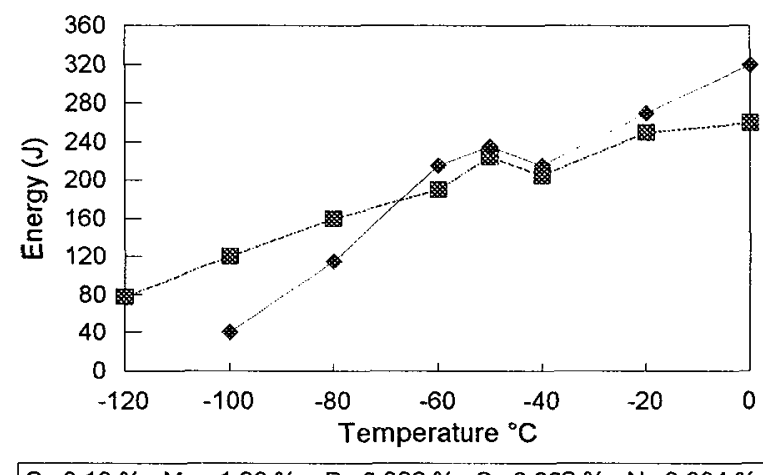

As delivered

Strain ageing : $5 \%+250^{\circ} \mathrm{C} / 1 \mathrm{H}$ 


\section{OFFSHORE STRUCTURAL STEEL PLATE - $60 \mathrm{~mm}$}

ISO-V Transverse Transition Curve

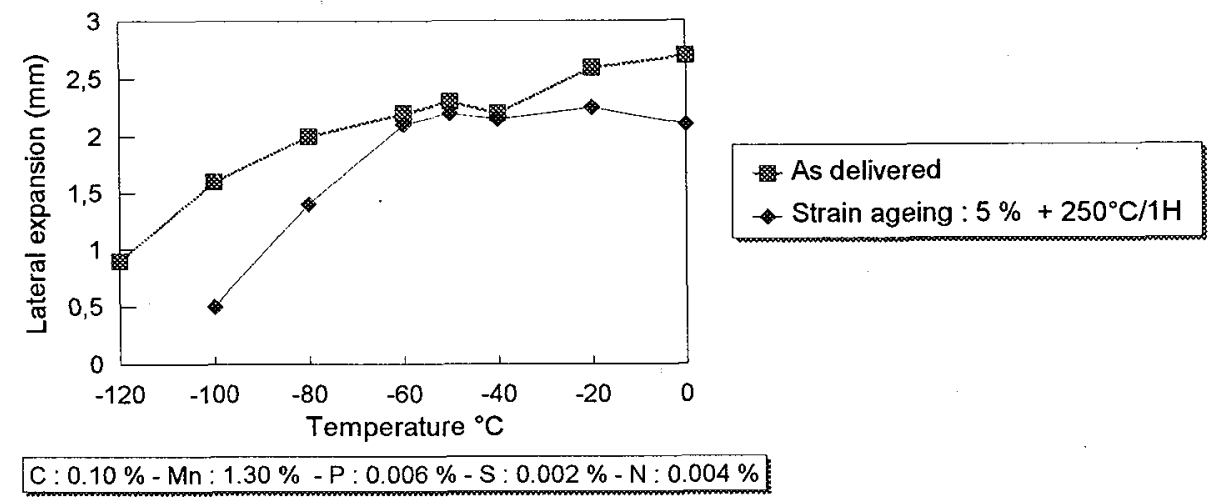

\section{OFFSHORE STRUCTURAL STEEL PLATE - $60 \mathrm{~mm}$}

ISO-V Transverse Transition Curve

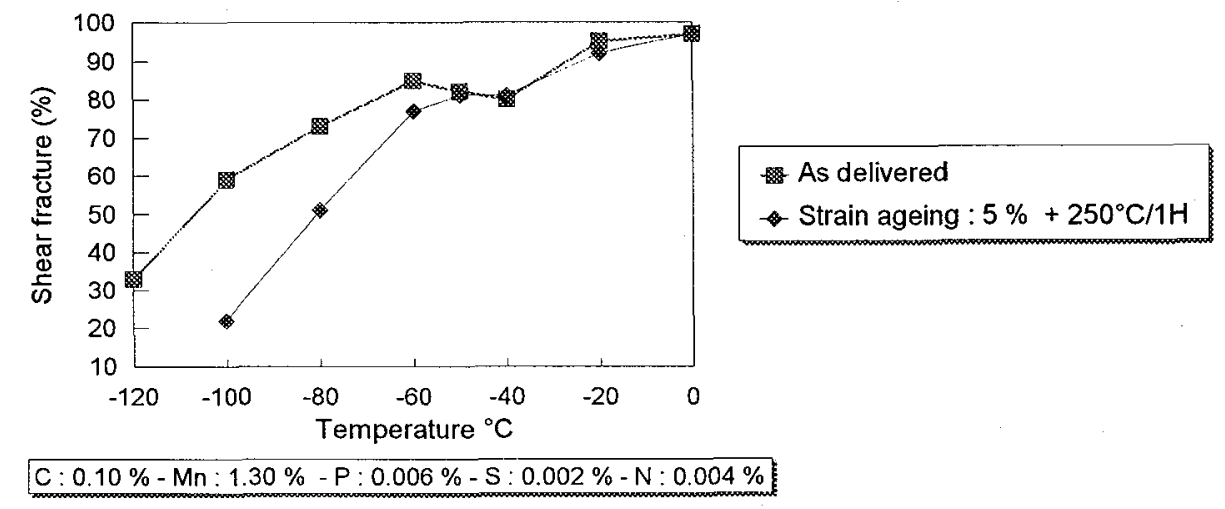




\section{Oxygen}

Throughout the melting and refining of liquid steel, phases of oxidation and deoxidation are used.

At the end of the ladle metallurgy, the oxygen content aimed at is very low in order to prevent the formation of oxyde inclusions; soluble oxygen at levels of $\mathbf{2}-\mathbf{5} \mathbf{~ p o m}$ need to be measured using electrolytic probes in order to make sure of achieving a total oxygen content below $20 \mathrm{pmm}$ at the final solidified stage after all possible reoxidation during continuous casting.

\section{Phosphorus}

+ Chromium - Molybdenum steels containing $11 / 4 \mathrm{Cr}-0.5 \mathrm{Mo}$ and $21 / 4 \mathrm{Cr}-1 \mathrm{Mo}$ are used in the petrochemical industry within a temperature range where temper embrittlement of the material can take place.

Extensive studies have shown that the temper embrittlement phenomenon of an increase of the transition temperature of the material after long exposure times at working temperature, resulting in brittle behaviour at ambiant temperature during commissioning-decommissioning periods, is strongly reduced and made acceptable if $\mathrm{J}$ and $\mathrm{X}$ factors are kept at low levels.

\begin{tabular}{|llcl|}
\hline $\mathrm{J}$ & $=$ & $\%(\mathrm{Mn}+\mathrm{Si}) \times(\mathrm{P}+\mathrm{Sn})$ & $<120$ \\
$\mathrm{X}$ & $=$ & $10 \mathrm{P}+5 \mathrm{Sb}+4 \mathrm{Sn}+\mathrm{As}$ & \\
& & 100 & $<15$
\end{tabular}

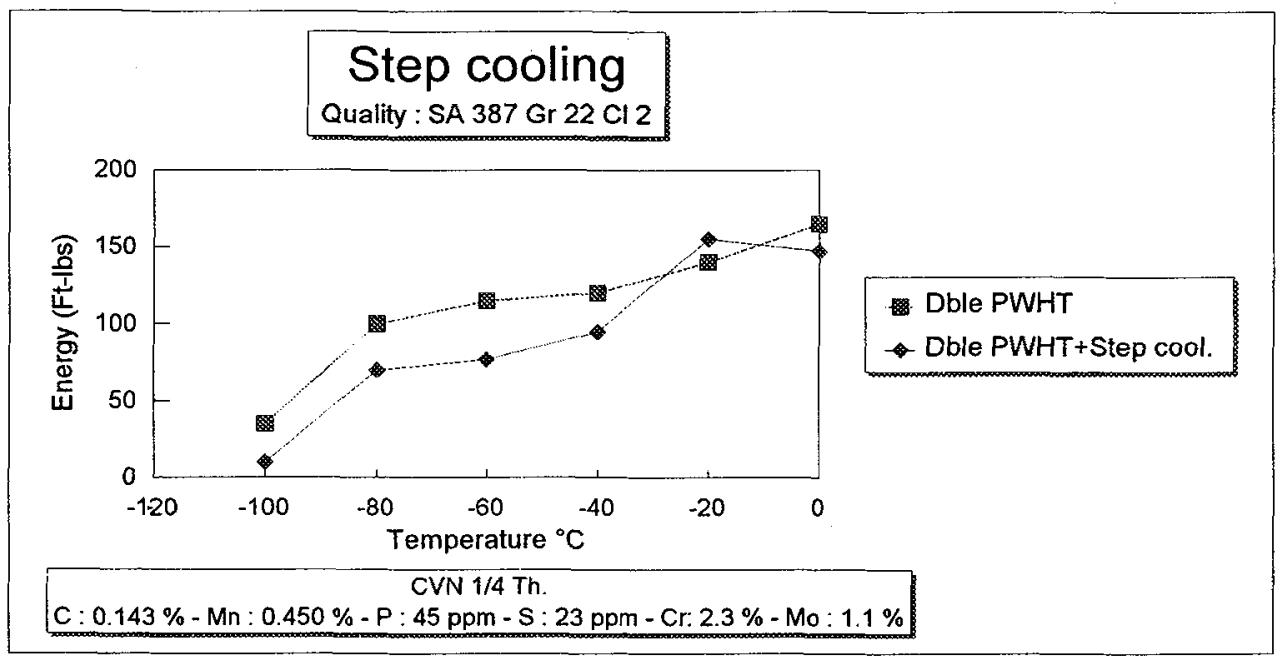






Since Silicon and Manganese contents cannot be reduced extensively so that the required mechanical characteristics of the material can be achieved, it is obvious that residual elements like $\mathrm{Sn}, \mathrm{As}, \mathrm{Sb}$ resulting from the melting of scrap must be reduced.

Phosphorus content weighs heavily in the $X$ factor and its reduction below 60 opm is one of the most effective means of reducing temper embrittlement.

+ Cryogenic $9 \% \mathrm{Ni}$ steels for LNG storage tanks have to show excellent toughness and fracture resistance at temperatures between -170 and $-196^{\circ} \mathrm{C}$.

It has been demonstrated that a CTOD value of $0.25 \mathrm{~mm}$ without any brittle event can only be achieved if the Phosphorus content of the steel is limited to $\mathbf{5 0} \mathbf{0 p m}$ maximum in addition to very low sulphur levels.

\section{Sulphur}

Probably one of the best known impurities in steel.

Its level in steel has been reduced dramatically thanks to optimum ladle metallurgy treatments using basic slags and Ca-injections.

Sulphur levels below $50 \mathrm{ppm}$ can prevent lamellar tearing of heavy products.

Sulphur levels below $20 \mathrm{ppm}$ enable low temperature $\left(-40^{\circ} \mathrm{C},-60^{\circ} \mathrm{C}\right)$ impact toughness to be achieved in unalloyed steels without the use of Ni-alloying.

In the case of Extra High Strength steels (EHS) with ultimate tensile strength in the range : $800-1500$ $\mathrm{N} / \mathrm{mm} 2$, impact toughness is also secured to temperatures down to $-40^{\circ} \mathrm{C}$.

Sulphur levels below $10 \mathrm{ppm}$ ensure the Hydrogen Induced Cracking (HIC) resistance of the steel.

When the material is used in sour gas service (large diameter offshore line pipes and pressure vessels), 

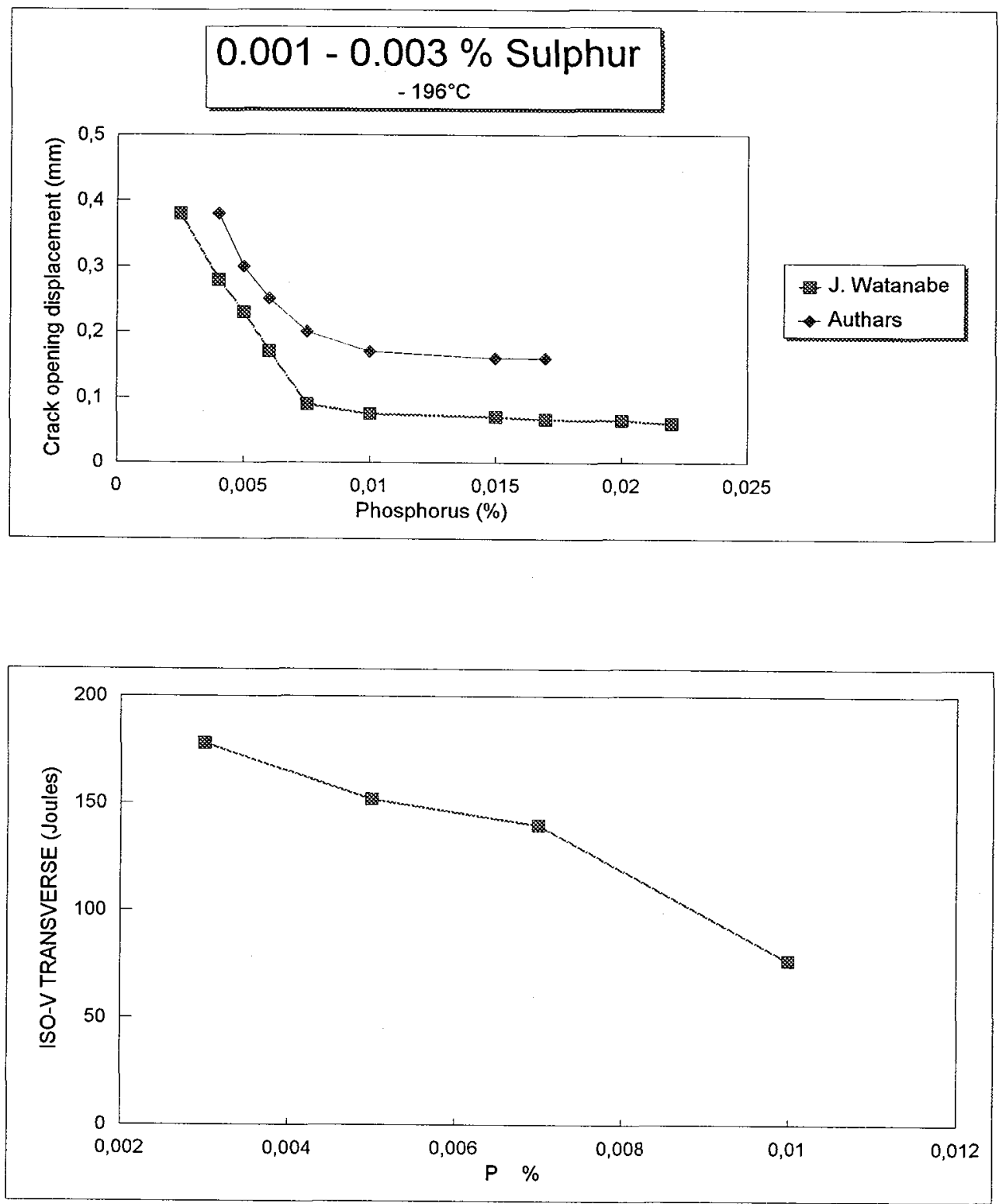
inclusion shape control is needed and achieved through $\mathrm{Ca}$ injection and oxygen content control through the following formula :

$$
\mathrm{ICP}=\mathrm{Ca} /((1.25 \times \mathrm{S})+(0.625 \times \mathrm{O}))
$$

in order to achieve globular inclusions.

\section{Titanium}

This element is more and more frequently used for binding interstitial elements like $\mathrm{C}$ and $\mathrm{N}$. Since the target levels aimed at are very low $(\approx 15 \mathrm{ppm})$, the Ti content must be regulated precisely in the range $\mathbf{3 0}$ $-60 \mathrm{ppm}$.

\section{CONCLUSIONS}

The difficulty of controlling elements such as Oxygen, Phosphorus, Sulphur, Aluminium, Titanium, Calcium at the level of traces or narrow range additions is linked to the reaction between slag and steel in the ladle.

All types of pollution through the slag itself, refractories, protecting powders and the atmophere must be analysed and measured.

This is where melting shops and quality control managers are currently exerting great efforts.

These efforts are now improving our understanding of inclusion morphology and its influence on the characteristics of materials.

All these improvements where controlled element content has been reduced to below 50 ppm have made it possible to achieve improved mechanical properties and service efficiency unforeseeable 10 years ago. This has been done under pressure from the users of steel materials, and with their cooperation.

We are now much closer to good understanding of steel behaviour for better use and development. 